\title{
The Use of Pontic Dialect Today
}

\section{Zoe Konstantinidou}

Aristotle University of Thessaloniki konstzoi@nured.auth.gr

\section{Argyris Kyridis}

Aristotle University of Thessaloniki akiridis@nured.auth.gr

\section{Doi:10.5901/mjss.2014.v5n8p627}

\begin{abstract}
Language and dialects are part of culture and civilization. That is why, the reasons for which they are used, are significant and closely related to their maintenance. This led us to the research the reasons of the use of pontic dialect today. For the purpose of our study we asked 259 speakers of pontic dialect, from Europe, Canada, Australia, Asia and United States of America, to inform us why and how do they still use this dialect. Speaker's responses show that the use of Pontic dialect today, is most supported by speakers for emotional and ideological reasons.
\end{abstract}

Keywords: pontic dialect, culture, civilization

\section{Introduction}

Language is defined as a system of points that helps communication between members of a group fellowmen and simultaneously becomes the spiritual culture developer, as a separate component of social or ethnic identity of a group of people (Koiliari, 2005).

For Saussure (1979), however, language has a trinity, as it is also inherent human ability, internalized mechanism, a product of social and achievement as an individual product. According to this aspect, language is a system of social product and therefore is linked to the society and also as individual embodiment associated with individuals, and therefore with society. The functions of language at the societal level are particularly important because it creates or strengthens dividing lines that unite the members of a linguistic community (Koiliari, 2005:38).

According to Haugen (1997) there are two distinct dimensions of the various uses of the terms language and dialect (in Kostoula-Makraki 2001:35). One is structural, and that means that describes the language itself, and the second is functional, that means that describes the social uses of language in communication (Kostoula-Makraki 2001:35).

So as languages are called linguistic varieties for political reasons, have the status of an official or national language. The varieties of the language are called dialects and have no differences with the language as regards grammatical structure and vocabulary. The term dialect is commonly used for geographical diversity, known as Geographical dialects, however there are other linguistic varieties such as 'koinoniodialektoi' (Chambers, Trudgill and Schilling-Estes, 2002; Auer, Hinskens and Kerswill, 2005). Each language has local variations and that is why we do not see it in exact form in different parts of the geographical area it covers. This is due to cultural, historical, political and geographical reasons.

\section{Pontic Dialect}

Geographical dialects constitute one dimension of linguistic heterogeneity (Tsokalidou, 2008). Greek language is divided into four geographical dialects: Pontic, Cappadocian, Tsakonic and the one for South Italy. All dialects and idioms of Modern Greek come from an evolutionary phase of the Common Hellenistic and Roman times through the Byzantine and formed during the late Byzantine period (Mackridge, 1991:335-336).

The dialect of Pontos (Pontic dialect) was used in some villages from inland of Asia Minor a depth of 100 kilometers from the coast, but mostly in northeastern Asia Minor Greek-speaking inhabitants of the Black Sea and 
specifically the eastern part of Asia Minor coast. This area comprised 800 villages, spread over an area of $400 \mathrm{~km}$ from the west to Inepoli Colchis in the east, and it was purely a Greek-speaking (Tompaidis, 1996). Because of the extensive geographical area where it had spread and lack of contact and communication between the speakers, had split in various idioms (Papadopoulos, 1953:86-93)

Last century Pontic dialect founded in such social, historical and political circumstances, that led to a structural and functional limitation. First years after the Treaty of Lausanne and the resettlement of Pontic Greeks in Greece, dialect's speakers communicated exclusively in their dialect. Over time, however, the need to communicate and contact with other Greek structures (public-state actors and social groups) that contributed most especially the younger ones to learn and common Greek (Tsokalidou and Chatzisavvedis, 2008:134). So today the dominant language of communication of virtually all speakers of the Pontic Greek, as languages that impair, almost always receive obediently the expansionism which the strong languages exercising (Chatzisavvedis, 1999:423-430).

The study of local dialects was neglected for many centuries (Kotsopoulos, 2001:3). Dealing with them began in the late 18th century in romantic era. The importance of Modern Greek dialects is significant not only linguistically and historically, but sociologically to.

The objective of this research was to investigate the use of the Pontic dialect in the current era. The reasons for which is still used, the social contexts in which it develops and its relationship to the cultural and national identity of its speakers.

\section{Research Methodology}

The survey involved 259 people, ages 16-65, from Greece, Turkey, the former Soviet Union and the Diaspora (USA, Canada, Australia and Europe).

All participants were given a questionnaire which completed anonymously and was divided into two parts. The first part (C) consisted of 26 closed questions Linkert type and the second ( 0 ) five open semi-structured questions. The survey was conducted from April to October 2012. The sample was in the form of random and convenient sample and according to geographical stratification provided the installation population (according Lavrentidis, 1972-1974).

Table 1. Demographic characteristics of sample

\begin{tabular}{|c|c|c|}
\hline Gender & $\mathbf{N}$ & $\%$ \\
\hline Male & 141 & 54.4 \\
\hline Female & 118 & 45.6 \\
\hline Total & 259 & 100.0 \\
\hline Age & $\mathrm{N}$ & $\%$ \\
\hline$<20$ & 39 & 15.1 \\
\hline $20-25$ & 16 & 6.2 \\
\hline $26-35$ & 56 & 21.6 \\
\hline $36-50$ & 87 & 33.6 \\
\hline$>50$ & 61 & 23.6 \\
\hline Total & 259 & 100.0 \\
\hline Educational Level & $\mathrm{N}$ & $\%$ \\
\hline Compulsory education & 42 & 16.2 \\
\hline High school & 108 & 41.7 \\
\hline University & 109 & 42.1 \\
\hline Total & 259 & 100.0 \\
\hline Profession & $\mathrm{N}$ & $\%$ \\
\hline Professional (scientific) & 16 & 6.2 \\
\hline Civil servant & 35 & 13.5 \\
\hline Private employee & 72 & 27.8 \\
\hline Freelance (craftsman) & 24 & 9.3 \\
\hline Farmer & 8 & 3.1 \\
\hline Unemployed-household & 36 & 13.9 \\
\hline Student & 40 & 15.4 \\
\hline Retired & 28 & 10.8 \\
\hline Total & 259 & 100.0 \\
\hline Pontic Active Member Association & $\mathrm{N}$ & $\%$ \\
\hline
\end{tabular}




\begin{tabular}{|ccc|}
\hline Yes & 130 & 50.2 \\
No & 129 & 29.8 \\
Total & 259 & 100.0 \\
\hline Country Of Origin & $\mathbf{N}$ & $\%$ \\
\hline Greece & 214 & 82.6 \\
Turkey & 4 & 1.5 \\
F.S.U. & 14 & 5.4 \\
Diaspora & 27 & 10.4 \\
Total & 259 & 100.0 \\
\hline Country Of Residence & $\mathbf{N}$ & $\%$ \\
\hline Greece & 197 & 76.1 \\
Turkey & 2 & 0.8 \\
F.S.U. & 0 & 00.0 \\
Diaspora & 60 & 23.2 \\
Total & 259 & 23.6 \\
\hline Place Of Origin & $\mathbf{N}$ & $\%$ \\
\hline Capital & 98 & 37.8 \\
Urban center & 74 & 28.6 \\
Town & 14 & 5.4 \\
Rural area & 73 & 28.2 \\
Total & 259 & 100.0 \\
\hline Country Of Origin & $\mathbf{N}$ & $\%$ \\
\hline Capital & 169 & 65.3 \\
Urban center & 40 & 15.4 \\
Town & 20 & 7.7 \\
Rural area & 30 & 11.6 \\
Total & 8 & 3.1 \\
\hline
\end{tabular}

\section{Findings and Discussion}

After content analysis, the responses were classified into categories and results show that factor "gender" is affecting the reason why speakers use Pontic dialect, and its association with the arts as a sign of culture. Specifically, it is observed that more women use it in order to maintain the tradition and culture, while more men are taking it as their native language. Both sexes, however, nearly $50 \%$ use it in their daily communication, but also to accurately express their thoughts.

Regarding age, the largest percentage of speakers seems to use it for communication purposes, emphasizing the age bracket 20-25 years who say they use it for sentimental reasons (31.6\%) and the over 50 years who stress of resolving native. Also, in small age categories up to 35 years, is observed the speakers' personal effort to learn the dialect, especially through sources, songs and questions to older people, as opposed to the following three categories in which the learning took place mainly through the narrow and extended family. Noteworthy is the fact that learning the dialect does not seem to be driven by cultural institutions (4.4\%) in any age group and especially at ages up to 25 years $(0-1.6 \%)$. Main source of learning and coherence with the Pontic dialect as a sign of culture, seems to be the music and singing (32.5\% and $28.3 \%$ respectively), mainly in the age to 25 years (54.4\% and $71.6 \%$ ) as speakers emphasized that through of these emerging lifestyle and thinking.

The educational level of the participants related to the way learning Pontic, with zero rates of compulsory education graduates to engage in personal effort, unlike graduates of Secondary and Third Grade. The immediate family is a key source of learning for all categories (51.1\%), with emphasis on the first (69.8\%), and once again the cultural organizations gather very low rates (4.4\%). The same happens with the factor "profession" where their contribution is low percentages $(0-10 \%)$. Here, while the effect of the immediate family environment is as intense in all professions, personal effort focuses mainly on occupation of farmers, freelances (craftsmen) and students. In the last two also observed, the effect of extended family, while the category of pensioners strongly influences and social environment.

These results contradict the indication of personal effort of speakers who are active members of cultural institutions (22.2\%). The latter primarily use the Pontic dialect for more to keep the tradition and culture and less emotional reasons, compared with speakers who are not active members particles and emphasize the address dialect as their mother tongue. However all express strong concern for its conservation (49.2\%) and the need to use (32.5\%), and observe how 
actively do not consider important means of preserving culture (12.9\%) that are non-active members (23.7 \%). Finally, regarding the association of dialect with the arts as a sign of culture, opinions converge, indicating absolute relevance (28.3\%), with music and song are the main means of preserving and conveying dialect smaller generations, not only bringing culture and lifestyle, but also attracting more easily and more directly to the candidate or potential speakers $(32.5 \%)$. The same is observed in the factor" country of origin".

On the other hand in the factor "country of residence", although it appears the intense concern for the conservation and use of dialect $(81.7 \%)$ is not considered as important means of preserving culture, mainly from residents of the Diaspora and Greece (18.2\%). Perhaps this is the reason why there is no intense personal effort for learning, especially in the Diaspora (0\%), but is achieved through the immediate family (56.1\%). Compared to its place of origin and residence personal effort focuses mainly on speakers originating or residing in the capital, while the social environment more conducive to learning in speakers originating from urban centers and speakers who reside in towns. Finally, unremarked can not stand the fact that once again we see the direct influence of close family in all categories, in contrast with cultural operators who remain uninvolved.

Table 2. Sig. open questions (O)

\begin{tabular}{|c|c|c|c|c|c|}
\hline & 01 & 02 & 03 & 04 & 05 \\
\hline Gender & .047 & & & & .008 \\
\hline Age & .003 & & .000 & & .003 \\
\hline Profession & .000 & & .049 & & \\
\hline Education Level & & & .004 & & \\
\hline Country of origin & & & & & .022 \\
\hline Country of residence & & & .013 & .023 & \\
\hline Place of origin & & & .028 & & \\
\hline Place of residence & & & .028 & & \\
\hline Active member & .003 & & .000 & .048 & .058 \\
\hline
\end{tabular}

Table 3. Analysis of categories and indicative answers of participants

\begin{tabular}{|c|c|c|}
\hline Questions & $\%$ & Indicative answers \\
\hline \multicolumn{3}{|r|}{ 01-Why Do You Use Potnic Dialect? } \\
\hline Liking & & I feel very nice when I use the pontic dialect \\
\hline Maintaining of tradition/culture & 26.2 & We use the Pontic dialect in order to keep alive our tradition \\
\hline Communication & 13.5 & $\begin{array}{l}\text { I use pontic dialect in order to talk with older people, but also to talk to my old friends } \\
\text { and friends from my village }\end{array}$ \\
\hline Sentimental reasons & 19.9 & $\begin{array}{l}\text { It's part of my life. When I use this dialect, I feel like I connect with something powerful. } \\
\text { It's something mine. }\end{array}$ \\
\hline Accuracy of expression & 14.8 & $\begin{array}{l}\text { I think this dialect is much richer than Greek language. Sometimes, it captures better } \\
\text { what I want to say. It is easier to define classifications and concepts. }\end{array}$ \\
\hline Native language & 17.4 & $\begin{array}{l}\text { I grew up listening to this dialect. For me it is my native language. It's a way of life for } \\
\text { me. }\end{array}$ \\
\hline \multicolumn{3}{|r|}{ O2-What Does Pontic Dialect Expresse For You? } \\
\hline Emotions & 13.4 & $\begin{array}{l}\text { When I use pontic dialect, I have strong feelings. I feel as if I open the door of my house. } \\
\text { It is the language of my soul and my heart. }\end{array}$ \\
\hline Origin & 73.4 & Is linking today with my past and my history. It reminds me that I am Pontic. \\
\hline Experiences & 13.4 & $\begin{array}{l}\text { Inside the Pontic dialect accumulate my personal experiences. I remember my } \\
\text { childhood in my village and my life there. }\end{array}$ \\
\hline \multicolumn{3}{|r|}{ 03-How Did You Learn Pontic Dialect? } \\
\hline Grandparents & 23.2 & $\begin{array}{l}\text { From grandfather and grandmother. I still remember that I was talking to them in Greek } \\
\text { and they answered me in Pontic dialect. That's how I learned. }\end{array}$ \\
\hline Parents & 27.9 & Since my parents were using pontic dialect inside the house. \\
\hline Family environment & 16.4 & From my aunts who were looking after me as I was o child. \\
\hline Social environment & 12.0 & I grew up in village, in an environment with Pontic refugees. It was inevitable. \\
\hline Cultural institutions & 4.4 & Through my involvement in Pontic associations. \\
\hline Personal effort & 13.1 & $\begin{array}{l}\text { By listening Pontic music. In order to grasp the meaning of the lyrics, I was trying to find } \\
\text { in formations about what did the lyrics mean. }\end{array}$ \\
\hline
\end{tabular}




\begin{tabular}{|c|c|}
\hline \multicolumn{2}{|r|}{ 04-What's Your Opinion About The Use Of Pontic Dialecct? } \\
\hline Concern for dialect's maintaining & 49.2 I try to use it and urge my children to use it too. Although, I fear that one day it will die. \\
\hline Necessity of dialect's using & 32.5 We have to use our dialect every day and in every occasion in order not to die. \\
\hline $\begin{array}{l}\text { Conservation tool of civilization } \\
\text { /culture }\end{array}$ & 18.3 It is our way of expression and our culture. \\
\hline \multicolumn{2}{|c|}{ 05-What's The Relation Between Pontic Dialect And Arts, As An Idication Of Culture? } \\
\hline Music & $\begin{array}{l}\text { The use of dialect becomes through music. That helps young people, to come in contact } \\
\text { with this dialect and learn it. }\end{array}$ \\
\hline Theatre & $\begin{array}{l}\text { Theater contains rich dialogues and scenes of daily life. This is a way to learn many } \\
\text { expressions of pontic dialect. }\end{array}$ \\
\hline Texts/Literature & There are few texts, but the written word helps you understand the structure. \\
\hline Dance & $\begin{array}{l}\text { T.9 The names of the dances and slogans motivate young people to come into contact with } \\
\text { the dialect. }\end{array}$ \\
\hline $\begin{array}{l}\text { Preservation/dissemination of } \\
\text { authentic information }\end{array}$ & $\begin{array}{l}\text { For us who are far away, and do not use much pontic dialect, art is the only way to keep } \\
\text { in touch with our language. }\end{array}$ \\
\hline Culture expression & 28.3 Through arts, broadcast messages and ideas. That's a way of culture expression. \\
\hline
\end{tabular}

On the other side, in the closed questions, results revealed that the educational level, the country of origin and the category in which the speakers belong, are most statistically significant differences. Meanwhile, questions about how to use the jargon, the use of the friendly and professional environment in everyday life with peers, but the connection to their ancestors and origin of speakers concentrate most differences.

More specifically, the sex factor seems to affect the use of the Pontic dialect by speakers to express themselves through music, with men to be better, while women seem to not use so only the dialect as men. However both sexes consider relevant dialect for expressing the music and culture, with men gather relatively larger percentages.

Very important for culture is considered the dialect from speakers over twenty years old, while neutral are the terms from younger ones. Average seems to be the exclusive use at ages 18-50 years, in contrast to speakers of over 50 years. Most seem to use the dialect to communicate with older people than with peers in all age categories except the speakers over 50 years, and just a few or none in the professional environment.

The factor "profession" seems to affect the use of the Pontic dialect and $70.2 \%$ of its speakers speaks from moderate to very daily, while in friendly and professional environment outweigh by far the farmers. The same happens in communicating with peers, except that a large proportion observed in the category of pensioners. As for the quality of use, seems that mainly pensioners and less farmers use it exclusively, while the other categories uses single words.

Regarding the educational level, the use in everyday life is greater, exclusive and also important for the culture in speakers who only completed compulsory education. From the other hand, is used less by speakers who completed tertiary education, especially in the wider social environment. However in all categories displayed a direct correlation to the use of dialect origin, culture, lifestyle and ancestors of speakers.

Undoubtedly the country of origin affects the use of dialect, and shows high rates in countries such as Turkey and the former Soviet Union, followed by Greece and the countries of the Diaspora. The same happens in the family, friendly and broad social environment and communication with peers and older people, while the highest rates are concentrated in the use for the purposes of expression through music in Greece and Turkey. Important for all countries, is connection dialect to the origin and the ancestors of the speakers. Exclusive observed to be using the main speakers in home country Turkey and the former Soviet United, while using individual words or simultaneous use of the mother tongue is mostly observed in Greece.

The same is observed to speakers residing in their respective countries. Very important as well, linking the dialect with the history of their country, their origin and their ancestors. There is little use by speakers of homogeneity in public places, but also in communicating with peers, while increasing the frequency of communication with older people.

Table 4. Sig. closed questions (C)

\begin{tabular}{lcccccccccc}
\hline Question & C1 & C2 & C3 & C4 & C5 & C6 & C7 & C8 & C9 & C10 \\
\hline Gender & & & & & .018 & & .014 & & & .017 \\
Age & & & & .003 & .003 & & & .000 & .015 & \\
Educational level & .007 & & .045 & .000 & .004 & .060 & & .000 & & \\
Profession & .031 & & & .002 & .001 & .011 & & .000 & & \\
Active member & & & & & & & & &
\end{tabular}




\begin{tabular}{|c|c|c|c|c|c|c|c|c|c|c|}
\hline $\begin{array}{l}\text { Country of origin } \\
\text { Country of residence } \\
\text { Place of origin } \\
\text { Place of residence }\end{array}$ & .000 & .000 & & .025 & & .008 & & $\begin{array}{l}.003 \\
.016\end{array}$ & $\begin{array}{l}.001 \\
.041\end{array}$ & .028 \\
\hline Question & C11 & C12 & $\mathrm{C} 13$ & C15 & $\mathrm{C} 17$ & C18 & C19 & $\mathrm{C} 24$ & $\mathrm{C} 25$ & $\mathrm{C} 26$ \\
\hline $\begin{array}{l}\text { Gender } \\
\text { Age }\end{array}$ & & & & & & $\begin{array}{l}.018 \\
.009\end{array}$ & & .014 & .018 & \\
\hline $\begin{array}{l}\text { Educational level } \\
\text { Profession } \\
\text { Active member }\end{array}$ & & .014 & .033 & .002 & .041 & $\begin{array}{l}.000 \\
.002\end{array}$ & .015 & .013 & .019 & .004 \\
\hline Country of origin & .001 & .005 & & & .024 & .000 & .017 & & & \\
\hline $\begin{array}{l}\text { Country of residence } \\
\text { Place of origin }\end{array}$ & .002 & .000 & & & .000 & .023 & .012 & & & \\
\hline
\end{tabular}

Speech is a skill that not only stems from, but also determines an influences social life. Languages are part of social behavior and most importantly communication system (Fragoudaki, 1987:24). Operate on a social scale which greatly influence and for this reason we observe correlations between linguistic and social behavior (Fishman, 1968:6).

The use of language is determined by social, geographical, chronological, stylistic and individual factors (Tsokalidou, Chatzisavvedis, 2008:21). According to Hymes $(1974 ; 2003)$, the use of a linguistic variety is determined by the social status of the speaker, but also by a number of factors relating to the time and space in which a communication takes place (setting / scene), participants (participants), the aim is to communicate this (end), the structure and content of the message (act sequence), the style in which a communication (key), the spoken or written means of communication (instrumentalities), the rules governing society (norms of interaction and interpretation) and the types of discourse (genre). Thus, the speakers use a form linguistic diversity depending on the occasion, in order to maintain control of situations.

The present investigation has shown that the use of the Pontic dialect is mainly for sentimental reasons and in order to maintain and transferred to future generations. Men speak more and most exclusive Pontic their communication and treat it as their native language. In the other hand, women though they use less, consider it very important for the preservation of tradition and culture. The communication relations have symbolic power which activates the relationships between speakers and govern the social groups to which they belong to (Koiliari, 2005:38). This effort often appears a strong mimetic availability from younger people, which is an effort to maintain the dialect and can then be converted to conscious effort, who takes the form of lived experience (Chatzisavvedis, 1995:47-72). Thus we observe mainly young people to make a personal effort to learn the dialect and via music and singing, and through them it seems that it can be expressed by culture and tradition. On the other hand, believed that music has the power to unite listeners and can attract new generations, giving incentives. When it does, the dialect is really to come into contact with the audience and grow.

Each ethnic group has its own way of musical expression (Kunst, 1950:7), and the main effect of music is that gives the listener a sense of security and connection to the place of origin, religion and the experiences that shape his personality (Lomax, 1959:929). In this way, the music associated with identity and memory. Has emotional connotations and can be used to claim and negotiate identity in a particular, but also powerful way (Baily, 1994:48). This is the reason why immigrant groups of multicultural cities often cling to their "traditional music" (Allen and Grose, 1988:4).

In everyday life, the speakers claim that they use the dialect minimally to moderately, mainly in family and friendly environment and with peers, more so use it to express themselves through music and to communicate with older people. In research that held in parts of Northern Greece highlights how Pontic used almost exclusively as an oral daily discourse and in particular between familiar persons and on special occasions communication. Such as greeting the start of a conversation, reference of stereotypical phrases, sayings, verses and songs that have no counterpart in the Greek language (Tsokalidou and Chatzisavvedis, 2008:135,143). This fact is emphasized by both genders but mostly by speakers over 36 years old and speakers engaged in technical and agricultural work. We see then, that culture and temperament of a cultural group are mirrored through the language and expressed its support through ceremonial lifestyle and the arts.

Participants connect dialect with local history, origin, ancestors, culture, way of life, cultural identity and considered important for their conservation. Moreover, the collective memory as a spoken word and not as recorded history has the power to shape cultural elements to new generations (Damanakis, 2009:146). However is not considered as important for communication with family-friendly environment and there is no use in the professional environment, public places and services.

Age, educational level and occupation affects equally the use of dialect, it seems that older speakers, pensioners 
and farmers prefer the use of the dialect for their daily communication. According to Tsokalidou and Chaztisavvidi (2008:143) production ratio in Pontic lags quantitatively and qualitatively at younger ages compared with the older and this maybe because after the exchange, in Greece there have been political, social and economic conditions which did not favor the Pontic dialect, since ceased to exist a geographical area in which they lived and were active only people who spoke pontic dialect (pontiofoni) (Ioannidis, 1988:33). This set functional dialect in decline. At the same time, as regards Greece who owns the majority of speakers, used the new Greek language at the same time the Pontic. As a result the Pontic dialect trongly felt in the younger generations. Instead, speakers from villages of Turkey where was spoken pontic dialect, but also areas of USSR to use more and most exclusive for their communications.

Although the linguistic heterogeneity in Greece, and in the Diaspora, has prevented the learning and use of dialect in the younger generations, was unable to erase it. This is probably due to the sentimental value attached by speakers in their dialect and the degree to which they associate with the cultural and national identity. Although the speakers in Greece recognize the Modern Greek as the dominant language (Ducrot and Todorov, 1972:417), attach to the Pontic, features and advantages. These beliefs are contributing to conservation and use, are the defense against the universal use of Modern Greek (Chatzisavvedis, 1995). On the other side Tsokalidou and Paparousi (2004:31) emphasize that language is a link between diasporas community and their homelands and how and if the conditions are not conducive to frequent the use, the speaker resists as it is an integral part of their culture. The relationship between language and society is so close that gives speakers that fell in that their language is a personal asset inherent in their existence, and only lost to death (Chatzisavvedis, 2009:6).

\section{Conclusions}

In conclusion, the use of Pontic dialect today is supported by speakers for emotional and ideological reasons. They associate with the cultural and national identity and maintaining necessary. In Greece, it seems that now is spoken as a second language in familiar environments, with strong influences of Modern Greek, as the latter can not be expressed with precision concepts and classifications resulting from the mentality and culture of its speakers. Younger generations look to it mainly through personal effort and through traditional music and song, while cultural institutions do not seem to help substantially to the rescue. The future is something that will be built in the spirit of continuity but also with profound transformations (Maalouf, 2009:57). It remains to see the future of the Pontic dialect.

\section{References}

Alle Ray. and Groce Nancy, 1998. 'Folk and traditional music in New York State', New York Folklore, 14(3-4): 1-6.

Baily John, 1994. 'The role of music in the creation of an Afghan national identity, 1923_/73', in Stokes, M. (ed.) Ethnicity, Identity and Music. The Musical Construction of Place . Oxford: Berg, 45-60

Ducrot Oswald, and Todorov Tzvetan, 1972. Dictionnaire enncyclopedique des sciences du lamguage, Paris, Seuil.

Kunst Jaap., 1950. Ethno-Musicology. The Hague: Martinus Nijhoff

Lomax Alan, 1959. 'Folk song style', American Anthropologist, 61(6): 927-54.

Saussure Ferdinand, 1979. Cours de linguistique generale, in Papazisis Stalin, I.B. (1975) Concerning Marxism in Linguistics (in Greek), Athens: Poria

Ioannidis Savvas, 1988. History and statistics of Trabzon and the surrounding area (in Greek). Thessaloniki, Kyriakidis

Laurentidis Isaak, 1972-1974. Refugees on exchange and exchangeable property (in Greek), Pontiaki Stoa, 2, 77-81.

Maalouf Amin, 1999. Vicious identities (in Greek). Publisher: Oceania, Athens.

Papadopoulos Anthimos, 1953. Features of Pontic dialect (in Greek)., Arxeion Pontou 18, б. 86-93

Tompaidis Dimitris, 1996. Pontic dialect (in Greek). In Pontic dialect Essays. Thessaloniki, Kodikas, pp. 227-229

Tompaidis Dimitris, 1988. Pontic dialect (in Greek). AӨńva, Arxeion Pontou.

Tsokalidou, R., Paparousi, M., 2004. Identity issues in the Greek diaspora. Language and literature (in Greek). Athens, Metexmio

Tsokalidou Roula, 2008. Sociolinguistics, language contact and language heterogeneity (in Greek).

Tsokalidou Roula, Xatzisavvidis Sofronis., 2008. Sociolinguistic Searches: research data (in Greek). Thessaloniki, Vanias

Fragoudaki Anna, 1987. Language and ideology, Fourth Edition (in Greek). Publisher: Ulysses.

Xatzisavvidis Sofronis., 1995. Pontic in Greece (in Greek). Arxeion Pontou, 46, 47-7 